Every slide and debacle is due to the combined effects of great drought succeeded by heavy wet. In the majority of the bogs, of any extent, and even in some of very small dimensions, there are in parts "shaky bogs." Those portions in great drought dry and contract, thereby being traversed by fissures, and more or less broken away from their soles. When the rains descend and the floods come, the water first saturates and floats the lower portions and afterwards the upper portions. The latter process has a peculiar appearance. When a bog is saturated, on its highest part there is generally a Loughaun, i.e. a pool without any surface outlet. During a drought the bog about the Loughaun sinks, while it often becomes quite dry ; but when the rains come, the bog swells just like a dry sponge put in water, and rises the Loughaun along with it. When a bog is saturated its lower portion is a sea of mud surrounded by a hard margin. If this margin in any place gives way there is a bursting forth ("debacle"), as in the recent case in Kerry, but sometimes the bog will over-swell, as in the case described by Molyneux, when the bog will begin "to walk" on its own account, and in its course lift up and carry away the barrier.

Different slides, such as that near Clara, that near Dunmore, and the recent one, were due to the turf-cutters, who weakened the barriers. Turf may be cut on two systems-." Brest banks," or banks opened round the margin of a bog or along a road; and banks that are more or less perpendicular to the margin of a bog or a bog road. The latter class of banks prevent slides, as they act as drains to the mass of the bog; while the Brest banks facilitate slides, as possibly may be exemplified this coming season, when the Brest banks are being cut.

Naturally it will be asked why all the bogs are not cut on the perpendicular system? The answer to which is, that it has been generally adopted in the mountain districts; but in the Low Land deep bogs this is nearly impracticable, as it would take years before you could run your bank into them, while all the time you would be at a dead loss. This, however, is a subject outside the present inquiry.

During my years of tramping the Irish hills, I have seen some interesting aspects of bog and drift slides; but it is unnecessary to recapitulate them here, as any one interested can fully read up the subject in previous publications.

It may, however, be allowable to point out that the different writers on the late Kerry debacle, apparently never saw the site of a previous debacle, or they would not make the foolish suggestions that have appeared in their writing.

I visited the Owenmore site about I 875 , or about fifty years after its occurrence. This is the most disastrous slide on record, as it carried away a whole village and its inhabitants, also a picket of Highlanders, whose bodies were afterwards pinked up in Tullaghan Bay. When I saw it there was nothing very remarkable about the bog; it had a nice hollow in it, with a pollagh for snipe and duck; but if I had not been told to the contrary, I would have seen nothing very extraordinary about it. Of similarly other sites that I have visited, that in the Joyce country is now a heathy hollow, a good place for grouse; while that on the Glencastle Hill slope, when visited ten years after, could scarcely be detected, except that at the north end of the townland, adjoining the road and Broad Haven, there was a tumbling up in hummocks, partly drift, partly bog.

A new gulch, due to a debacle, is hard to cross, if not impassable, for a year or two; after which time the bog will have soaked, and the bog-mould slopes will begin to consolidate and grow vegetation; once they have a sod on them all appearances of the debacle rapidly disappear, so much so, that only one person out of a hundred, if you undertook to explain to him what had formed a gulch in a mountain slope, would believe you ; the other ninety-nine would say "Hookey Walker!"

The bog, the site of the recent slide, is not more than 20 or 30 feet deep; this will contract at each side of the gulch so as to leave a hollow not more than from 10 to 15 feet deep, as has elsewhere been practically proved.

G. Henry Kinahan, District Surveyor (Retired), H.M. Geol. Survey.

\section{On the Goldbach-Euler Theorem concerning Primes.}

I HAVE verified the new law for all the even numbers from 2 to I000, but will not encumber the pages of NATURE with the retails. The approximate formula hazarded for the number of resolutions of $2 n$ into two primes, viz. $\frac{\mu^{2}}{n}$, where $\mu$ is the number of mid-primes, does not always come near to the true value. I have reasons for thinking that when $i$ is sufficiently great, $\frac{\mu^{2}}{2 n}$ may possibly be an inferior limit. The generating function

$$
\left[\sum_{1-x^{p}}\right]^{2}
$$

given in a recent number of NATURE, p. 196, is subject to a singular correction when the partible number $2 n$ is the double of a prime. In this case, since the development to be squared is

$$
\mu+x^{n}+x^{2 n}+\ldots+x^{p}+x^{2 p}+\ldots+\text { + \&c., }
$$

the coefficient of $x^{2 n}$ will contain $2 \mu$, arising from the combination of $o$ with $2 n$, which is foreign to the question, and accordingly the result given by the generating function would be too great by $2 \mu$.

This may be provided against by always rejecting the centre of the mid-range from the number of mid-primes. The formula will then in all cases give twice the number of ways of breaking up $2 n$ into two unequal primes. Another method would be to take as the generating function not the square of the sum, but the product of the fractions $\frac{I}{1-x^{p}}$ (without casting out $n$ when it is a prime), but this method would be inordinately more difficult to work with in computing series involving the roots of unity than the one chosen, which is in itself a felicitous invention. ${ }^{1}$ Whether the method turns out successful or not, it at the very least gives an analytical expression for the number of ways of conjoining the mid-primes to make up $2 n$ without trial, which in itself is a somewhat surprising result. Having lost my preliminary calculations, it may be some little time before I shall be able to say whether the method does or does not contain a proof of the new theorem; but that this can be ascertained, there is no manner of doubt. This is the first serious attempt to deal with Euler's theorem, or to bring the question into line with the general theory of partitions.

It is proper to regard the range I to $2 n-I$ as consisting of two complementary flank regions, two lateral mid-prime regions, and a region reduced to a single term in the middle, as ex.gr.

Or, again,

$$
\text { I, 2, 3:4, 5:6:7,8:9, IO, I1. }
$$

$$
\text { I, 2, 3:4, 5, 6:7:8, 9, 10:11, 12, 13. }
$$

And the question of $2 n$ being resoluble into 2 primes breaks up into three, viz. whether $2 n$ can be composed with two flank primes, two lateral mid-primes, or with the number in the central region repeated.

Some slight corrections are required in the preceding note in NATURE. P. I96, 1. 5 of letter, for "improved method" read "original method"; 1. 7, for "demonstration" read "denumeration" ; 1.24 , omit the words "with the exception of $2 n=2$." Also, p. $197,1.3$, for " $\rho e^{\theta}$ " read " $\rho e^{t}$."

January $\mathbf{I}$.

\section{J. J. Sylvester.}

\section{Patterns produced by Charged Conductors on} Sensitive Plates.

In the course of a recent $\mathrm{X}$-ray lecture demonstration, I accidentally got what is, so far as I know, a novel, and certainly an interesting result. IHaving taken a radiograph of three small wire skeletons enclosed in cardboard bodies, on the developed plate (covered with a plain glass pressed upon the film) being put into the lantern, I noticed the precipitated silver particles set themselves in certain lines. These radiated normally from the skulls and limbs of the figures, and in the more open parts of the background set themselves into a key or fret pattern. I concluded, on further examination, that this effect was probably due to a state of electric strain induced by the Röntgen tube, but it was only upon the softening of the gelatine film by the heat of the lantern that the particles were set free, so as to obey the electric impulse to which they were subjected.

This led me to experiment upon the effect produced by charged conductors on sensitive plates, with the final result of

1 For the generating function we may take any power greater than 2 instead of the square, and the coefficient of $x^{2 n}$ will then be the number of instead of the square, and the coefficient of $x^{2 n}$ will then be the number of couples making up $2 n$ multiplied by $\left(r^{2}-\gamma\right) \mu r^{-1}$, which can be calculated by the same method as for the square, but is more difficult and must give rise to numerous theorems of great interest, arising from the multiform representation of the same quantity. 